\title{
An Essential Role of Angiotensin II Receptor Type 1a in Recipient Kidney, Not in Transplanted Peripheral Blood Leukocytes, in Progressive Immune-Mediated Renal Injury
}

\author{
Yutaka Hisada, Takeshi Sugaya, Sumiko Tanaka, Yusuke Suzuki, Chisei Ra, \\ Kenjiro Kimura, and Akiyoshi Fukamizu
}

Discovery Research Laboratory (YH, TS, ST), Tanabe Seiyaku Company, Ltd., Osaka; Division of Nephrology (YS), Department of Medicine, Juntendo University School of Medicine, Tokyo; Department of Molecular Cell Immunology and Allerology (CR), Advanced Medical Research Center, Nihon University, Tokyo; Nephrology (KK), Postgraduate School of Medicine, The University of Tokyo, Tokyo; and Institute of Applied Biochemistry and Tsukuba Advanced Research Alliance (AF), University of Tsukuba, Ibaraki, Japan

SUMMARY: Despite an intensive effort of elucidating the pathogenic role of angiotensin II (All) in immune-mediated renal injury, the precise mechanisms are poorly understood. In the present study, we examined the site of All action, peripheral blood leukocytes or resident renal cells, in immune-mediated renal injury using All type 1a receptor (AT1a)-deficient homozygous (AT1a $-/-)$ mice and wild-type $($ AT1 $\mathrm{a}+/+)$ mice. The AT1a $-/-$ mice showed delayed-type hypersensitivity similar to that of the AT1a $+/+$ mice, suggesting that the lack of AT1a does not impair a Th1-type cellular immune response of peripheral blood leukocytes involved in immune-mediated renal injury. We then generated the radiation bone marrow chimera mice, WA and AW, which have transplanted peripheral blood leukocytes from the AT1a $+/+$ and AT1a $-/-$ mice into the AT1a $-/-$ and AT1a $+/+$ mice, respectively. As controls, WW and AA, the AT1a +/+ and AT1a $-/-$ mice given bone marrow cells from the AT1a $+/+$ and AT1a $-/-$ mice, respectively, were generated. Seven days after induction of antiglomerular basement membrane nephritis, glomerulosclerosis observed in the WW mice was markedly ameliorated in the WA mice, but not in the AW mice. In addition, the recruitment of monocytes/macrophages and the expressions of monocyte chemoattractant protein-1 and intercellular adhesion molecule-1 in the glomeruli of the AW and WW mice was evident, but such significant phenotypes were not seen in the WA and AA mice, showing a marked amelioration of renal injury dependent on the host AT1a genotype. These results demonstrate an essential role of AT1a in intrinsic renal cells for progressive immune-mediated renal injury and indicate a beneficial effect of blocking the renin-angiotensin system in the treatment of such diseases. (Lab Invest 2001, 81:1243-1251).

\begin{abstract}
$A$ ngiotensin II (All), a bioactive peptide in the reninangiotensin system, plays a key role in hemodynamic regulation such as the control of blood pressure, salt, and fluid homeostasis (Griendling et al, 1996; Hall and Guyton, 1990; Timmermans et al, 1991). Accumulating evidence indicates that All also has nonhemodynamic actions, promoting cell growth and extracellular matrix protein synthesis (Matsusaka et al, 1996; Owens, 1989). These biologic actions of All are mediated predominantly by AT1 subtype receptors (Griendling et al, 1996; Timmermans et al, 1991). In rodents, AT1 exists as two isoforms, AT1a and AT1b, encoded by two different genes (Iwai and Inagami, 1992; Sasamura et al, 1992); AT1a has predominantly physiologic roles in the mouse (Burson et al, 1994). Thus, we generated an AT1a-deficient
\end{abstract}

Received May 31, 2001.

Address reprint requests to: Dr. Takeshi Sugaya, Discovery Research Laboratory, Tanabe Seiyaku Company, Ltd., 16-89, Kashima-3-chome, Yodogawa-ku, Osaka 532-8505, Japan.E-mail:t-sugaya@tanabe.co.jp mouse strain and found it to be a highly useful model for analyzing All functions (Sugaya et al, 1995).

Previously, we have shown that renal injuries were significantly ameliorated when antiglomerular basement membrane (GBM) nephritis was induced in AT1a-deficient homozygous (AT1a -/-) mice, as compared with wild-type (AT1a $+/+)$ mice. To exclude the effect of difference in blood pressure between the AT1a +/+ and AT1a -/- mice, we induced anti-GBM nephritis in the AT1a +/+ mice whose blood pressure was kept lower than that of the AT1a -/- by administration of hydralazine. As a result, the hypotensive AT1a $+/+$ mice showed similar renal injury to those of the normotensive AT1a $+/+$ mice, indicating that even the AT1a +/+ mice with blood pressure lower than that of the AT1a $-/-$ mice could develop renal injuries similar to those of the normotensive AT1a $+/+$ mice, and that the effects of blood pressure do not have a profound effect on the induction of anti-GBM nephritis (Hisada et al, 1999). The result indicated to us that All plays a pathogenic role in immune-mediated renal injury, at least in part independent of blood pressure 
effects. Consistent with our results, pharmacologic studies have shown that the agents that inhibit All function (All type 1 receptor antagonists) also reduce renal injury in anti-GBM nephritis (Suzuki et al, 1998; Yayama et al, 1995). These results suggest that All plays an important role in immune-mediated renal injury.

Studies to date have shown that All mediates immunologic responses, such as increased production of proinflammatory mediators, increased proliferation of splenic lymphocytes, and activation of macrophages (Hahn et al, 1994; Klahr and Morrissey, 1998; Nataraj et al, 1999). In addition, the blockade of All function results in the amelioration of several immunemediated diseases, including chronic allograft rejection and myocarditis (Amuchastegui et al, 1998; Furukawa et al, 1996; Nataraj et al, 1999), leading to the speculation that All plays a pathogenic role in immune-mediated renal injury through the effects on peripheral blood leukocytes.

In progressive renal injury, resident renal cells, such as mesangial and endothelial cells, play an important role and All regulates their cellular function (Matsusaka et al, 1996). Therefore in the present study we focused on which cells (ie, peripheral blood leukocytes or resident renal cells) All exerts its effects in immune-mediated renal injury. For this purpose, using the AT1a $-/-$ and AT1a $+/+$ mice, we generated radiation bone marrow chimera mice that lack $A T 1 a$ in peripheral blood leukocytes or resident renal cells (recipient kidney) by bone marrow transplantation (BMT), and examined the site of All action in immunemediated renal injury. The results demonstrate that All action mediated by AT1a in the recipient kidney is essential for progressive immune-mediated renal injury.

\section{Results}

\section{Delayed-Type Hypersensitivity}

For the first set of experiments, we examined the Th1-type cellular immune response that has been reported to be involved in the induction of anti-GBM nephritis (Coelho et al, 1997; Huang et al, 1994; Lewis and Couser, 1971). The delayed-type hypersensitivity (DTH) was analyzed by the response to sheep red blood cells (SRBC) as described in "Materials and
Methods." The AT1a $-/-$ and AT1a +/+ mice showed similar swelling of the left footpad in response to SRBC (Table 1). To further analyze cellular immune response, we examined the production of interferon- $\gamma$ $(\mathrm{IFN}-\gamma)$ by T-cell-enriched splenocyte that is induced by Th1 subset of $\mathrm{T}$ helper cells (Cher and Mosmann, 1987). T-cell-enriched splenocytes from the AT1a $-/-$ and AT1a +/+ mice preimmunized with rabbit IgG were stimulated with rabbit IgG, and then the production of IFN- $\gamma$ was evaluated as described in "Materials and Methods." The production of IFN- $\gamma$ by T-cell-enriched splenocytes from the AT1a +/+ mice was increased by the stimulation of rabbit IgG. A similar increase in the production was observed in the T-cell-enriched splenocytes from the AT1a -/- mice (Table 1). From these results, it is suggested that the AT1a -/- and AT1a +/+ mice have similar Th1-type cellular immune responses.

\section{Generation of Radiation Bone Marrow Chimera Mice and Genotype Exchange of Peripheral Blood Cells}

We then generated radiation bone marrow chimera mice that lack AT1a in peripheral blood leukocytes or recipient kidney by BMT. The AT1a $+/+$ mice that received the bone marrow cells from the AT1a $+/+$ and AT1a -/- mice were designated as WW and AW mice, respectively. Likewise, the AT1a $-/-$ mice transplanted with the bone marrow cells from the AT1 $\mathrm{a}+/+$ and AT1a -/- donor mice were designated as WA and AA mice, respectively. To confirm the replacement of peripheral blood cells in recipient mice with those of donor mice, genotype exchange of peripheral blood leukocytes was evaluated before the induction of nephritis. PCR was performed using specific primers that detect the AT1a or lacZ genes (Fig. 1A). In the peripheral blood leukocytes from the AW mice, the primers detected the 1134-bp fragments corresponding to the amplified products of the lac $Z$ gene. Alternatively, the primers detected the 770-bp amplified fragments derived from the AT1a gene in the peripheral blood leukocytes from the WA mice, verifying the successful replacement of the genotype of the peripheral blood leukocytes in the recipient mice by that of the donor mice (Fig. 1B).

Table 1. Cellular Immune Response in the AT1a-/- and AT1a+/+ Mice

\begin{tabular}{|c|c|c|c|c|}
\hline \multirow[b]{2}{*}{ Mouse } & \multirow[b]{2}{*}{$N$} & \multirow[b]{2}{*}{$\mathrm{DTH}^{a}(\mathrm{~mm})$} & \multicolumn{2}{|c|}{$\begin{array}{l}\text { IFN- } \gamma \text { production } \\
\left(\mathrm{pg} / 2.0 \times 10^{6} \text { cells }\right)\end{array}$} \\
\hline & & & control & rabbit IgG \\
\hline $\mathrm{AT} 1 \mathrm{a}+/+$ & 5 & $0.94 \pm 0.08$ & $4.9 \pm 0.8$ & $20.6 \pm 8.8$ \\
\hline AT1a-/- & 5 & $1.01 \pm 0.06$ & $5.1 \pm 0.4$ & $16.6 \pm 3.4$ \\
\hline
\end{tabular}

\footnotetext{
${ }^{a}$ Cutaneous delayed-type hypersensitivity (DTH) response to sheep red blood cells (SRBC) was examined as described in "Materials and Methods." The thickness of the left and right footpad was measured and the DTH response was evaluated by subtracting the right footpad thickness from that of the left footpad.

${ }^{b}$ Antigen-specific production of IFN- $\gamma$ by T-cell-enriched splenocytes. The splenocytes from the AT1a+/+ and AT1a-/- mice immunized with rabbit IgG and cultured in the presence of $20 \mu \mathrm{g} / \mathrm{ml}$ of rabbit IgG for 24 hours under the serum-free conditions as described in "Materials and Methods." As a control, the splenocytes were cultured in the absence of rabbit IgG (control). All data are mean \pm SE. No statistical difference between the AT1a $+/+$ and AT1a $-/-$ mice, as assessed by the Student's $t$ test.
} 
A

AT1a (+)

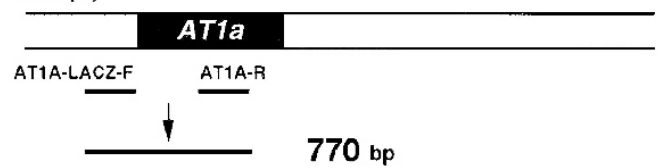

AT1a (-)

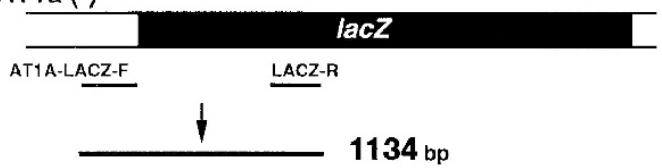

B

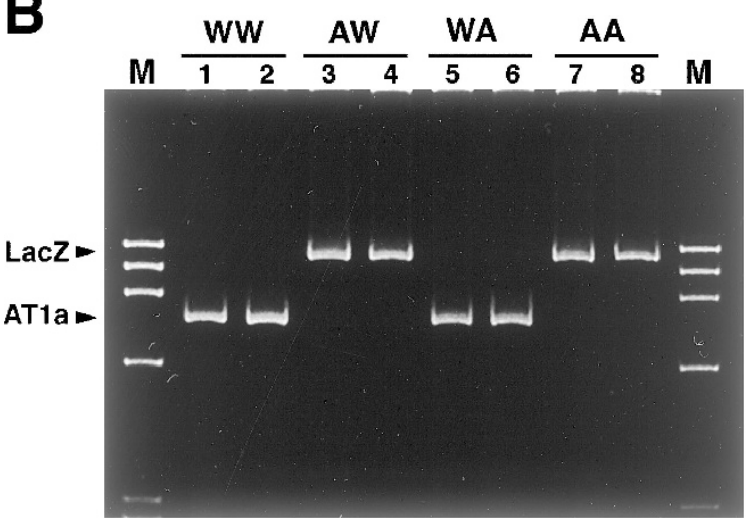

Figure 1.

Genotype exchange of peripheral blood cells in radiation bone marrow chimera mice. A, Schematic presentation of specific primers that detect the AT1a and lacZ genes. One set of primers, AT1A-LACZ-F and AT1A-R, detects a 770-bp fragment of the AT1a gene, and another set, AT1A-LACZ-F and LACZ-R, detects a 1134-bp fragment of the lacZ gene. B, PCR amplification of the AT1a and lacZ genes. Genomic DNA prepared from peripheral blood cells was amplified using specific primers (a mixture of AT1A-LACZ-F, AT1A-R, and LACZ-R). Lanes 1 and 2, WW mice; Lanes 3 and 4, AW mice; Lanes 5 and 6 , WA mice; Lanes 7 and 8, AA mice. M, $\phi$ X174 HaellI-digested fragments. Two representative results for each animal group are shown.

\section{Estimation of Circulating Antirabbit IgG Antibody}

To evaluate the humoral immune response of peripheral blood leukocytes in immune-mediated renal injury, we examined the production of autologous antibody against rabbit IgG immunized for the induction of nephritis, which has been recognized to be important for immune-mediated renal injury (Unanue and Dixon, 1965). The results are shown in Table 2 . There was no significant difference in the amount of total lgG against rabbit IgG among the WW, AW, WA, and AA mice. We then examined the production of $\lg \mathrm{G} 1$ and $\lg \mathrm{g} 2 \mathrm{a}$ against rabbit IgG that are induced by Th2- and Th1-type cytokines, respectively (Finkelman et al, 1990; Mosmann and Coffman, 1989). No difference in the production of $\lg G 1$ and $\lg \mathrm{G} 2 \mathrm{a}$ was observed among the WW, AW, WA, and AA mice, suggesting similar Th2- and Th1-type responses in the peripheral blood leukocytes lacking AT1a. To confirm that there was no difference in autologous antibody production in experimental groups, we examined their deposition on glomeruli. As shown in Figure 2, similar glomerular deposition of $\lg \mathrm{G} 1$ and $\lg \mathrm{G} 2 \mathrm{a}$ autologous antibody was observed among the WW, AW, WA, and AA mice. The deposition of total IgG was also similar (data not shown). From these results, it is indicated that the lack of AT1a in peripheral blood leukocytes did not affect their function to produce autologous antibody in the induction of nephritis.

\section{Light Microscopy}

To examine the site of All action (ie, peripheral blood leukocytes or resident renal cells) in glomerular injury, we compared glomerular histologic changes in the AW and WA mice with those of the WW mice. Glomerulosclerosis was evaluated as described in "Materials and Methods." The results are shown in Figure 3 and Table 3. The WW mice showed severe glomerulosclerosis. The AW mice lacking AT1a in the peripheral blood leukocytes developed comparable glomerulosclerosis. In contrast, these histologic changes were markedly ameliorated in the WA mice that lack AT1a in resident renal cells. These results indicate that the lack of AT1a in the resident renal cells, not in the peripheral blood leukocytes, results in the marked amelioration of glomerular injury.

\section{Urinary Protein Excretion}

To further examine renal injury, the amount of protein excreted into urine was measured. Consistent with ameliorated renal injury in the anti-GBM nephritis induced in the AT1a -/- (Hisada et al, 1999), the urinary protein excretion of the AA and WA mice $(0.29$ \pm 0.08 and $0.21 \pm 0.1 \mathrm{mg} / 24$ hours $/ \mathrm{g}$ body weight at 7 days, respectively) was drastically reduced as compared with the WW and AW mice $(0.84 \pm 0.14$ and $0.77 \pm 0.18 \mathrm{mg} / 24$ hours $/ \mathrm{g}$ body weight, respectively) (Fig. 4A). These results indicate that the decreased urinary protein excretion in the AA and WA mice is due to the lack of AT1a in the resident renal cells, not in the peripheral blood leukocytes.

Table 2. Production of Antibody against Rabbit $\lg G^{a}$

\begin{tabular}{ccccc}
\hline Group & $N$ & Total IgG & $\operatorname{lgG1}$ & $\operatorname{lgG} 2 \mathrm{a}$ \\
\hline WW & 5 & $136.8 \pm 4.1$ & $75.1 \pm 4.2$ & $25.7 \pm 0.1$ \\
AW & 6 & $143.9 \pm 6.7$ & $80.0 \pm 4.5$ & $30.7 \pm 1.0$ \\
WA & 5 & $129.1 \pm 16.1$ & $73.4 \pm 8.1$ & $30.3 \pm 2.8$ \\
AA & 6 & $153.5 \pm 4.1$ & $90.4 \pm 1.6$ & $32.7 \pm 2.6$ \\
\hline
\end{tabular}

${ }^{a}$ The production of autologous antibody against rabbit IgG was examined by colorimetric analysis using ELISA for mouse IgG, IgG1, and IgG2a, as described in "Materials and Methods." The level of antibody production was estimated by comparing the initial velocity of the increase in absorbance at OD650 (m0D/minute). Data are mean \pm SE. No statistical difference between animal groups as assessed by the Tukey's multiple comparison test. 
A
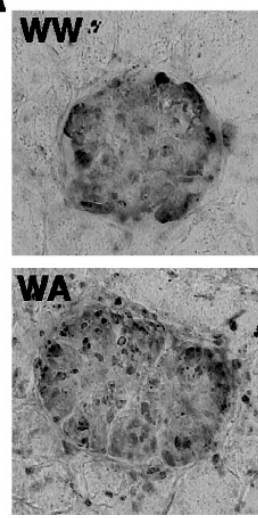
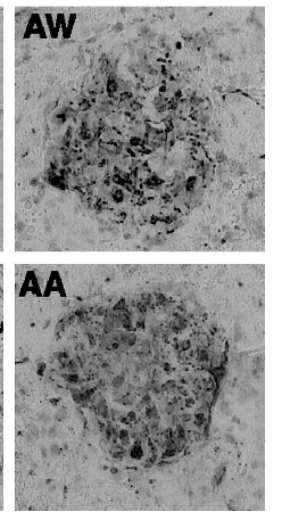

B
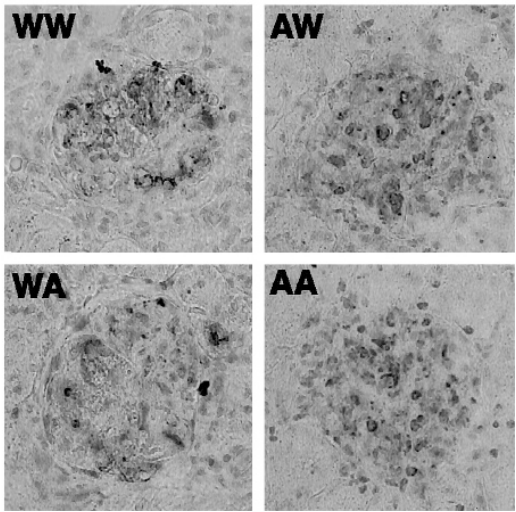

Figure 2.

Glomerular deposition of autologous antibody. Immunohistochemistry of IgG1 (A) and IgG2a (B) antibody against rabbit IgG was performed using frozen sections. The WW, AW, WA, and AA mice showed similar glomerular deposition of IgG1 and IgG2a autologous antibody against rabbit IgG. Original magnification, $\times 400$.

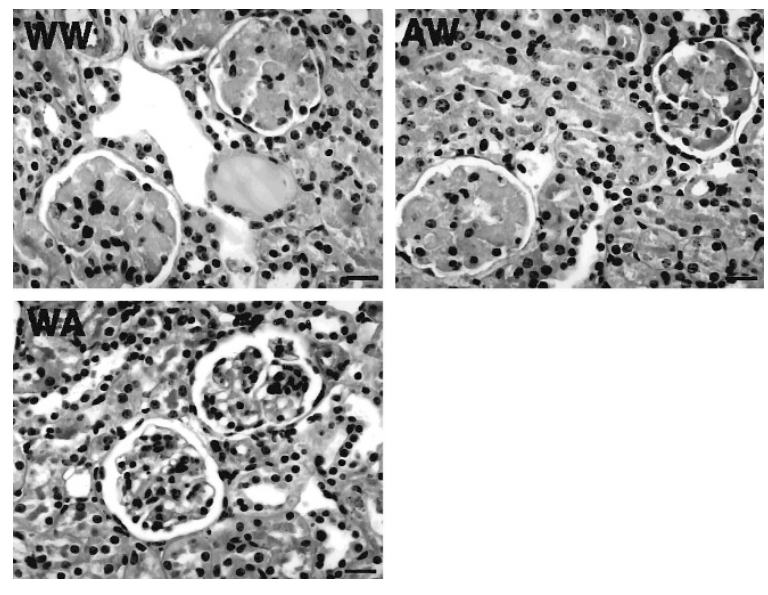

Figure 3.

Light microscopy. Paraffin-embedded sections $4 \mu \mathrm{m}$ thick were stained with periodic acid $<\mathrm{n}>$ Schiff's reagent. The WW mice showed severe glomerulosclerosis. The AW mice developed glomerulosclerosis similar to that in the WW mice. The glomerulosclerosis was markedly ameliorated in the WA mice. The length of bars is $20 \mu \mathrm{m}$.

Table 3. Evaluation of Glomerulosclerosis

\begin{tabular}{lccc}
\hline & WW & AW & WA \\
\hline Score & $70 \pm 5$ & $69 \pm 9$ & $6 \pm 2^{b}$ \\
$N$ & 5 & 6 & 5 \\
\hline Glomerulosclerosis score was determined as described in "Materials and \\
Methods." \\
${ }^{a}$ Data are the mean \pm SE. \\
${ }^{b} p<0.01$ vs the WW mice as evaluated by the Dunnett's multiple \\
comparison test.
\end{tabular}

\section{Serologic Study}

There was no significant difference in the amount of blood urea nitrogen (BUN) among the animal groups before the induction of nephritis. At Day 7, the WW and $A W$ mice showed a dramatic increase in the amount of BUN. In contrast, BUN in the WA and AA mice was not significantly increased even at Day 7 (Fig. 4B). These results, together with those of urinary protein excretion, confirmed that the lack of AT1a in resident renal cells, not in peripheral blood leukocytes, results in the marked reduction of renal injury.

\section{Glomerular Recruitment of Monocytes/Macrophages}

To examine the glomerular recruitment of monocytes/ macrophages $(\mathrm{Mo} / \mathrm{M} \phi)$, an important pathogenic feature of immune-mediated renal injury (Cotran, 1978; Schreiner et al, 1982), immunohistochemistry using F4/80 monoclonal antibody was performed. As shown in Figure 5, the number of F4/80 positive cells in the AW mice was not significantly different from that in the WW mice $(1.83 \pm 0.08$ and $1.75 \pm 0.14$ cells $/$ glomerular cross-section in the AW and WW mice, respectively). In contrast, the WA mice showed a marked reduction of $F 4 / 80$ positive cells $(0.27 \pm 0.03$ cells/ glomerular cross-section) as compared with the WW and AW mice, but the number of F4/80 positive cells was similar to that in the AA mice $(0.23 \pm 0.02$ cells/glomerular cross-section). These results indicate that the glomerular recruitment of $\mathrm{Mo} / \mathrm{M} \phi$ was significantly decreased in the WA and AA mice that lack AT1a in resident renal cells.

\section{Glomerular Expressions of MCP-1 and ICAM-1}

The expressions of monocyte chemoattractant protein-1 (MCP-1) and intercellular adhesion molecule-1 (ICAM-1) in glomeruli of the kidney represent a potential clue to elucidate the mechanism by which All is involved in the glomerular recruitment of $\mathrm{Mo} / \mathrm{M} \phi$, because up-regulation of MCP-1, a chemotactic protein for $\mathrm{Mo} / \mathrm{M} \phi$ (Yoshimura et al, 1989), and ICAM-1, an adhesion molecule well known to mediate the adhesion of $\mathrm{Mo} / \mathrm{M} \phi$ to endothelial cells (Brady, 1994), is shown to be important in their recruitment (Kawasaki et al, 1993; Tang et al, 1996). The expressions of MCP-1 and ICAM-1 were dramatically increased in glomeruli of the WW and AW mice, but reduced in the WA and AA mice (Fig. 6, A and B, left). Semiquantitative analysis is shown for the expressions 
A

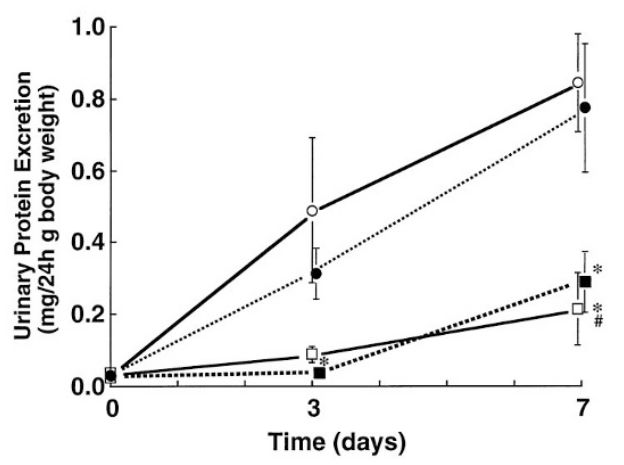

B

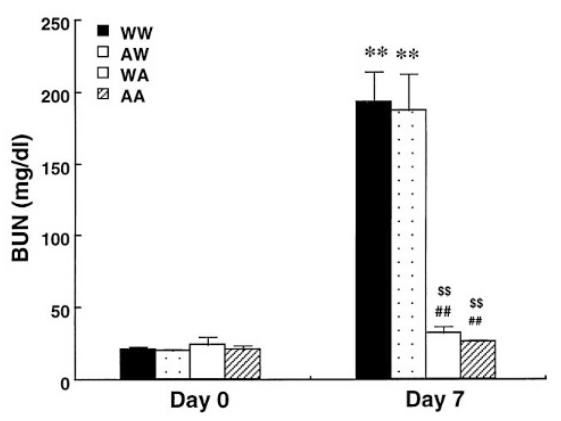

Figure 4.

Changes in urinary protein excretion and blood urea nitrogen (BUN). A, The mice were housed in individual metabolic cages before (Day 0 ) and 6 days after the induction of nephritis. Urine samples were collected for 24 hours. The amount of protein excreted into urine was determined. The open circles and open squares represent WW and WA mice, respectively. The closed circles with a dotted line and the closed squares with a dotted line represent AW and AA mice, respectively. ${ }^{\star} p<0.05,{ }^{* \star} p<0.01$ vs WW mice; $\# p<0.05$, \#\#p<0.01 vs AW mice, as determined by the Tukey's multiple comparison test. B, Blood samples were collected from the eyeground and the abdominal large vein before (Day 0 ) and 7 days after the induction of nephritis, respectively. The amount of BUN was measured using the Wako Urea NB kit. The closed, dotted, open, and hatched bars represent the WW, WA, AW, and AA mice, respectively. ${ }^{* \star} p<0.01$ vs Day 0 , as determined by Student's $t$ test, $\# \# p<0.01$ vs WW mice, $\$ \$ p<0.01$ vs AW mice at Day 7 , as determined by the Tukey's multiple comparison test.

\section{A}
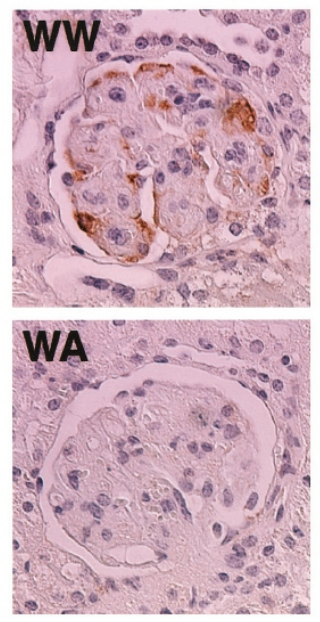
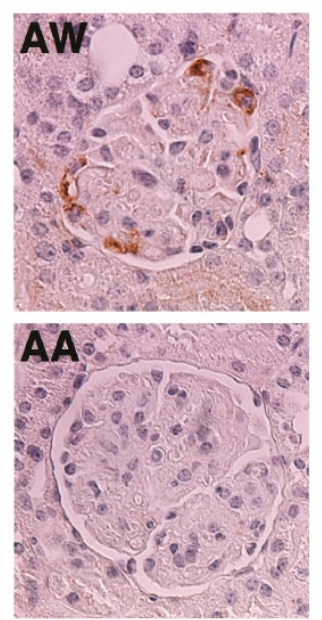
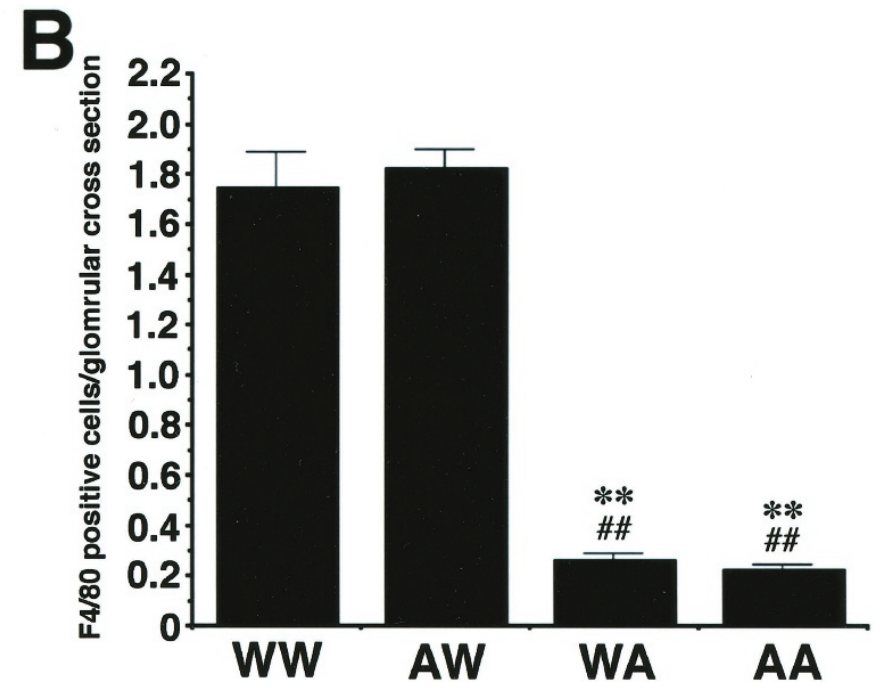

Figure 5.

Glomerular recruitment of monocytes/macrophage (Mo/M $\phi)$. A. Immunohistochemistry of Mo/M $\phi$ using the rat monoclonal antibody to mouse macrophage (F4/80) was performed on Day 7. Original magnification, $\times 400$. B. The number of $\mathrm{Mo} / \mathrm{M} \phi$ per glomerular cross-section was determined in at least 40 glomeruli in each

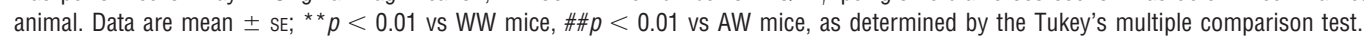

of MCP-1 and ICAM-1 in Figure 6, A and B, right, respectively.

\section{Discussion}

The potential roles of All in immune-mediated diseases have long been discussed because All modulates several immune cell functions such as proliferation, cytokine production, chemokinesis, and increase in the activity of inflammatory enzymes (Goetzl et al, 1980; Nataraj et al, 1999; Scheidegger et al, 1997; Vance and Kelly, 1994), through AT1a that is expressed in immune cells, including lymphocytes and macrophages (Costerousse et al, 1993; Gomez et al,
1993; Tsutsumi et al, 1992; Vance and Kelly, 1994). We have recently shown that the kidney in AT1a $+/+$ mice was severely injured by the induction of antiGBM nephritis, but not in AT1a -/- mice (Hisada et al, 1999). By allowing the selective replacement of bone marrow-derived cells, including $\mathrm{Mo} / \mathrm{M} \phi$, BMT provides an approach to distinguish the roles of donor immune cells from those of recipient kidney cells in immune-mediated renal injury. In the present study, we examined the site of All action in immunemediated renal injury using radiation bone marrow chimera mice that lack AT1a either in peripheral blood leukocytes or recipient kidney by BMT. The main 
A

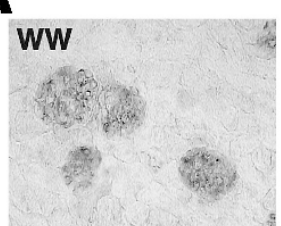

WA

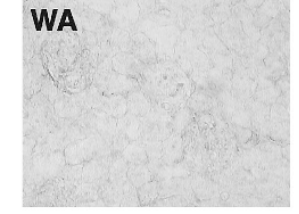

B
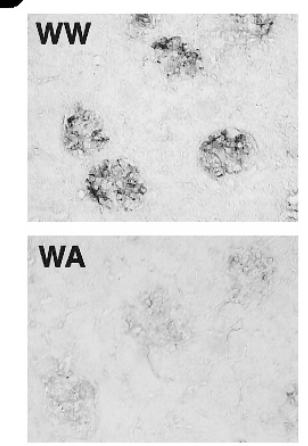

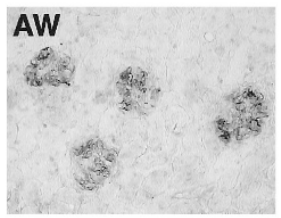

AA
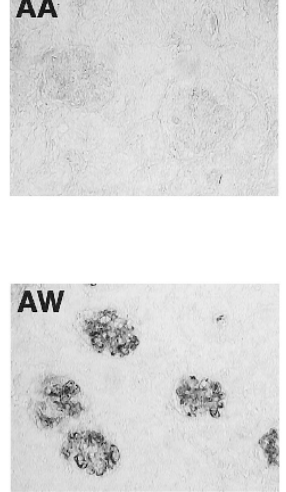

AA
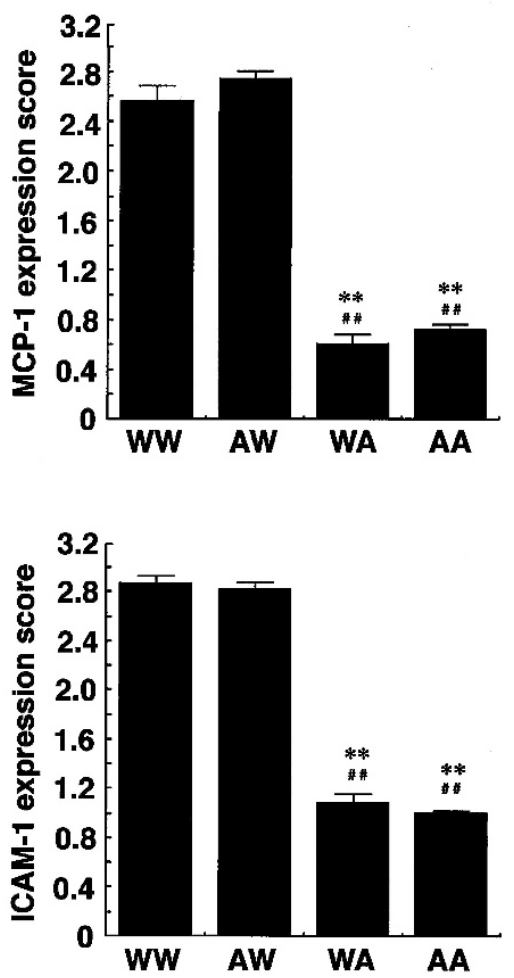

Figure 6.

Glomerular expressions of monocyte chemoattractant protein-1 (MCP-1) and intercellular adhesion molecule-1 (ICAM-1). Immunohistochemistry of MCP-1 (A, left) and ICAM-1 (B, left) was performed using frozen sections. Whereas WW and AW mice showed strong mesangial expression of MCP-1, WA and AA mice exhibited its significant reduction. Similarly, the strong expression of ICAM-1 was observed in endothelial cells of WW and AW mice, but was markedly reduced in WA and AA mice. Original magnification, $\times 200$. Quantitative analysis of the expressions of MCP-1 (A, right) and ICAM-1 (B, right) was performed as described in "Materials and Methods." Data are mean $\pm \mathrm{SE} ;{ }^{* *} p<0.01$ vs WW mice, \#\#p<0.01 vs AW mice, as determined by the Tukey's multiple comparison test.

finding of this work is that All plays an essential role in recipient kidney (resident renal cells), but not in peripheral blood leukocytes, in immune-mediated renal injury.

Studies to date have suggested the effect of All on the function of peripheral blood leukocytes. A recent study using AT1a-deficient mice illustrated that the effects of All on peripheral blood leukocytes, such as the stimulation of splenic lymphocytes proliferation, are involved in allograft rejection of cardiac transplantation (Nataraj et al, 1999). However, in our current study, the lack of AT1a in peripheral blood leukocytes does not impair the cellular and humoral immune responses in immune-mediated renal injury. DTH response to SRBC in the AT1a - /- mice was comparable to that in the $A T 1 a+/+$ mice. Supporting this result, T-cell-enriched splenocytes from the AT1a $-/-$ and AT1a +/+ mice produced a similar amount of IFN- $\gamma$ by the stimulation of immunized antigen. In humoral immune response, the production of total $\operatorname{lgG}, \lg G 1$, and $\lg G 2 a$ against rabbit $\lg G$ and their deposition on glomeruli in the mice lacking the AT1a in peripheral blood leukocytes (AW and AA mice) were similar to those in the mice with intact expression of AT1a (WW and WA). These results suggest that All does not affect the cellular and humoral immune responses in our study. Thus, the effect of All on peripheral blood leukocytes mediated by AT1a is unlikely to be critical in immune-mediated renal injury.

Glomerulosclerosis, urinary protein excretion, and serum BUN were markedly reduced in the WA mice. In contrast, the AW mice showed glomerulosclerosis, urinary protein, and serum BUN similar to the WW mice, wild-type control mice that express AT1a in both recipient kidney cells and peripheral blood leukocytes. These results clearly indicate the essential role of AT1a in recipient kidney, but not in peripheral blood leukocytes, in immune-mediated renal injury.

Although the expression of MCP-1 and ICAM-1 in glomeruli increased in the recipient kidney of AT1a $+/+$ mice when anti-GBM nephritis was induced, the lack of AT1a led to the inactivation. Furthermore, the ability of $\mathrm{Mo} / \mathrm{M} \phi$ transplanted from AT1a $-/-$ mice to be recruited to glomeruli was retained in AW mice, similar to that seen in WW mice, but not in AA nor WA mice. These findings therefore suggest that All modulates the expression of MCP-1 and ICAM-1 in recipient kidney cells and provides an environment to recruit $\mathrm{Mo} / \mathrm{M} \phi$ into glomeruli.

One striking finding of the present study is the apparent effect of All emerging in the progressive immune response. There are two distinct immune responses in immune-mediated renal injury (Unanue and Dixon, 1967). The initial phase response is ob- 
served at the onset of immune-mediated renal injury. As we reported previously, both AT1a $+/+$ and AT1a $-/-$ mice showed similar acute phase response on the early onset of induced anti-GBM nephritis (Hisada et al, 1999). Consistent with this result, we have also shown the critical role of All-independent immunecomplex signaling mediated by Fc $\gamma$ chain in the acute phase (Suzuki et al, 1998). These observations suggest that the acute phase immune response is, at least in part, independent of All effects. After this, the immune response is propagated in the progression phase. Subsequent pathologic changes, such as glomerular recruitment of $\mathrm{Mo} / \mathrm{M} \phi$, glomerular expressions of MCP-1 and ICAM-1, urinary protein excretion, the elevation of BUN, and glomerulosclerosis, emerge during the progressive immune response, where All plays an important role. All may propagate immune reaction after initial immune responses to induce immune-mediated renal injury.

In conclusion, AT1a for All action in the recipient kidney is essential for progressive immune-mediated renal injury, and the prevention of the reninangiotensin system may be of benefit for the treatment of such disorders.

\section{Materials and Methods}

\section{Animals and Reagents}

AT1a -/- and AT1a +/+ mice were described previously (Sugaya et al, 1995). Mice at 8 to 10 weeks of age were used for the studies. All animal experiments were approved by local review boards. The quality of all the reagents used in the study is guaranteed by the manufactures, and we used them before the guarantee of the reagent quality expired.

\section{DTH}

DTH was examined by responses to SRBC. The AT1a $-/-$ and AT1a $+/+$ mice were immunized with SRBC $\left(1 \times 10^{7}\right.$ cells $)$ in the left footpad. Five days later, $1 \times$ $10^{8}$ cells of SRBC were injected into the plantar surface of the left foot. As a control, the right footpad was injected with saline. Twenty-four hours later, the thickness of the left and right footpad was measured with a dial thickness gauge (Ozaki Manufacturing, Tokyo, Japan). DTH was evaluated by subtracting the right footpad thickness from that of the left footpad. Five AT1a $-/-$ and AT1a +/+ female mice were used in the experiment.

\section{Antigen-Specific IFN- $\gamma$ Production by Splenic T Cells}

The AT1a -/ - and AT1a +/+ mice were immunized subcutaneously with $0.3 \mathrm{mg}$ of rabbit $\lg \mathrm{G}$ in each flank, and seven days later, rabbit IgG (500 $\mu \mathrm{g})$ was injected into the left footpad. The mice were killed 48 hours after the injection of rabbit IgG into the left footpad. Spleens removed aseptically were disrupted into single cells in RPMI1640 medium containing 10\% FCS. After erythrocytes were removed with Gay's solution $\left(0.13 \mathrm{M} \mathrm{NH}_{4} \mathrm{Cl}, 5 \mathrm{~mm} \mathrm{KCl}, 0.84 \mathrm{~mm} \mathrm{Na}_{2} \mathrm{HPO}_{4}\right.$,
$0.17 \mathrm{~mm} \mathrm{KH}_{2} \mathrm{PO}_{4}, 5.5 \mathrm{~mm}$ glucose, $1 \mathrm{~mm} \mathrm{MgCl}, 0.28$ $\mathrm{mm} \mathrm{MgSO} 4,1.5 \mathrm{~mm} \mathrm{CaCl}_{2}, 13.4 \mathrm{~mm} \mathrm{NaHCO}_{3}$ ), the cell suspension was subjected to nylon fiber column (Wako Pure Chemical Industries, Osaka, Japan) to enrich T cells. The enriched T cells were then stimulated with $20 \mu \mathrm{g} / \mathrm{ml}$ of rabbit lgG, and cultured for 24 hours under serum-free conditions. The amount of IFN- $\gamma$ in culture supernatant was determined using an IFN- $\gamma$ ELISA kit (Genzyme Corporation, Cambridge, Massachusetts).

\section{Generation of Radiation Bone Marrow Chimera Mice}

BMT was performed using 10-week-old female mice. Bone marrow cells were collected from the AT1a -/and AT1a +/+ mice and were treated with Gay's solution to exclude the contamination of red blood cells. The bone marrow cells were then transplanted intravenously to the recipient mice, which had been irradiated with x-ray at 12 Gy. There was no symptom of graft-versus-host-disease in any of the mice. For the following experiments, five WW and WA mice and six $A W$ and $A A$ mice were used.

\section{Examination of Genotype Exchange of Peripheral Blood Leukocytes}

The genotype exchange of peripheral blood leukocytes was examined by PCR using genomic DNA prepared from peripheral blood leukocytes before induction of anti-GBM nephritis. Genomic DNA was prepared using the QIAamp Blood Kit (Qiagen, Valencia, California). Because the AT1a gene was replaced with the lac $Z$ gene by homologous recombination in the AT1a -/- mice, PCR was performed to detect the AT1a or lacZ genes in wild-type and AT1a-deficient genotypes, respectively. The sequence of each primer was as follows: forward primer for the AT1a and lacZ genes (AT1A-LACZ-F) that is not contained in the AT1b gene; 5'-AGTGCATTTTGAACAGTGTCTG-3', reverse primer for the AT1a gene (AT1A-R); 5'ATCCTAAAGATGTCATCATTTC-3', reverse primer for the lacZ gene (LACZ-R); 5'-CAGAGGATGATGCTCGTGACGG-3'.

\section{Induction of Anti-GBM Nephritis}

Anti-GBM nephritis was induced in the WW, AW, WA, and AA mice as described previously (Hisada et al, 1999). In brief, mice were preimmunized with rabbit IgG (Organon Teknika, Westchester, Pennsylvania). Five days after the immunization, anti-GBM antiserum was administered intravenously by the tail vein. Mice were killed at Day 7 after the induction of anti-GBM nephritis. Urine samples were collected before, and 2 and 6 days after the induction of nephritis. Serum samples were collected before and 7 days after the induction of nephritis.

\section{Estimation of Autologous Antibody Production}

The production of antibody against rabbit IgG preimmunized to induce renal injury was examined as 
described previously (Hisada et al, 1999) using serum samples collected at Day 7. In brief, 96-well ELISA plates coated with rabbit IgG (Organon Teknika) were incubated with test plasma. After being washed extensively with PBS containing $0.05 \%$ Tween-20, the plates were incubated with horseradish peroxidaseconjugated antibodies against mouse IgG (SigmaAldrich Japan K.K., Tokyo, Japan), mouse IgG1 (Serotech, Oxford, United Kingdom), and mouse IgG2a (Zymed Laboratories, San Francisco, California). A kinetic analysis of absorbance at $650 \mathrm{~nm}$ was performed using 3,3',5,5'-tetramethylbenzidine (Nacalai Tesque, Kyoto, Japan) as a substrate. The level of autologous antibody production was estimated by comparing the initial velocity of the increase in absorbance at $650 \mathrm{~nm}$. The glomerular deposition of autologous antibody was examined by immunohistochemistry. Frozen sections $8 \mu \mathrm{m}$ thick were incubated with peroxidase-conjugated rabbit antibody against mouse IgG1 (Serotech) and mouse IgG2a (Zymed Laboratories). After extensive washing, peroxidase enzyme was detected using 3,3'-diaminobenzidine tetrahydrochloride (Wako Pure Chemical Industries) as a substrate.

\section{Light Microscopy}

Paraffin-embedded sections $4 \mu \mathrm{m}$ thick were stained with periodic acid $<\mathrm{n}>$ Schiff's reagent to assess histologic changes. Glomerulosclerosis was scored in a blind fashion by an observer. One hundred glomeruli were examined for each kidney and the degree of glomerular sclerosis was determined for each kidney. Glomerulosclerosis in each glomerulus was graded as "0" if of normal area, "1" if mildly increased in area, "2" if moderately increased in area, or " 3 " if markedly increased in area. A composite sclerosis score was then calculated for each kidney according to the following formula: $0 \times$ (number of grade 0 glomeruli) + $1 \times$ (number of grade 1 glomeruli) $+2 \times$ (number of grade 2 glomeruli) $+3 \times$ (number of grade 3 glomeruli).

\section{Immunohistochemistry}

For immunohistochemical examination of glomerular $\mathrm{Mo} / \mathrm{M} \phi$ infiltration, the kidneys were fixed with $10 \%$ buffered formaldehyde, embedded in paraffin, and 4- $\mu \mathrm{m}$-thick sections were prepared. The sections were then subjected to brief trypsinization and serial incubations with $\mathrm{F} 4 / 80$, a rat monoclonal antibody that recognizes mouse macrophage (clone A3-1; Serotec) and a biotin-conjugated antirat IgG (Santa Cruz Biotechnology, Santa Cruz, California), and processed using a streptavidin-biotin immunoperoxidase kit (Vector Laboratories, Burlingame, California). The number of $\mathrm{Mo} / \mathrm{M} \phi$ per glomerular cross-section was counted for at least 40 glomeruli in each animal. The immunohistochemistry of the glomerular expressions of MCP-1 and ICAM-1 was examined as described previously using goat polyclonal antibodies against MCP-1 and ICAM-1 (Santa Cruz Biotechnology), respectively (Hisada et al, 1999). The glomerular expres- sions of MCP-1 and ICAM-1 were semiquantitatively evaluated using a photoimaging system (Imaging Research, St. Catharine's, Ontario, Canada) as described previously (Hisada et al, 1999).

\section{Determination of Urinary Protein Excretion Rate and Serologic Study}

Urine samples were collected for 24 hours as described previously (Hisada et al, 1999). The amount of protein excreted into urine was determined using a protein assay kit (Nippon Bio-Rad Laboratories, Tokyo, Japan). The amount of BUN was determined using the Wako Urea N B kit (Wako Pure Chemical Industries).

\section{Statistical Analysis}

The results are expressed in the text as the mean \pm SE. The Student's $t$ test (Stat View 4.5; Abacus Concepts, Berkeley, California) was used to compare the means of the two groups. The statistical difference in the score for glomerulosclerosis between the WW and AW mice or between the WW and WA mice was evaluated by the Dunnett's multiple comparison test (SAS Institute, Cary, North Carolina). Tukey's multiple comparison test (SAS Institute) was used to determine the significance of differences in other histologic changes between groups. $p<0.05$ was considered significant.

\section{Acknowledgements}

We would like to thank N. Kashihara and M. Nangaku for helpful discussions. We also extend our gratitude to T. Shibata, N. Kobayashi, and Y. Kanamaru for excellent technical assistance.

\section{References}

Amuchastegui SC, Azzollini N, Mister M, Pezzotta A, Perico N, and Remuzzi G (1998). Chronic allograft nephropathy in the rat is improved by angiotensin II receptor blockade but not by calcium channel antagonism. J Am Soc Nephrol 9:1948-1955.

Brady HR (1994). Leukocyte adhesion molecules and kidney diseases. Kidney Int 45:1285-1300.

Burson JM, Aguilera G, Gross KW, and Sigmund CD (1994). Differential expression of angiotensin receptor $1 A$ and $1 B$ in mouse. Am J Physiol 267:E260-E267.

Cher DJ and Mosmann TR (1987). Two types of murine helper T cell clone. II. Delayed-type hypersensitivity is mediated by TH1 clones. J Immunol 138:3688-3694.

Coelho SN, Saleem S, Konieczny BT, Parekh KR, Baddoura FK, and Lakkis FG (1997). Immunologic determinants of susceptibility to experimental glomerulonephritis: Role of cellular immunity. Kidney Int 51:646-652.

Costerousse O, Allegrini J, Lopez M, and Alhenc-Gelas F (1993). Angiotensin I-converting enzyme in human circulating mononuclear cells: Genetic polymorphism of expression in T-lymphocytes. Biochem J 290:33-40.

Cotran RS (1978). Monocytes, proliferation, and glomerulonephritis. J Lab Clin Med 92:837-840. 
Finkelman FD, Holmes J, Katona IM, Urban JF, Beckmann MP, Park LS, Schooley KA, Coffman RL, Mosmann TR, and Paul WE (1990). Lymphokine control of in vivo immunoglobulin isotype selection. Annu Rev Immunol 8:303-333.

Furukawa $\mathrm{Y}$, Matsumori $\mathrm{A}$, Hirozane $\mathrm{T}$, and Sasayama $\mathrm{S}$ (1996). Angiotensin II receptor antagonist TCV-116 reduces graft coronary artery disease and preserves graft status in a murine model: A comparative study with captopril. Circulation 93:333-339.

Goetzl EJ, Klickstein LB, Watt KW, and Wintroub BU (1980). The preferential human mononuclear leukocyte chemotactic activity of the substituent tetrapeptides of angiotensin II. Biochem Biophys Res Commun 97:1097-1102.

Gomez RA, Norling LL, Wilfong N, Isakson P, Lynch KR, Hock R, and Quesenberry P (1993). Leukocytes synthesize angiotensinogen. Hypertension 21:470-475.

Griendling KK, Lassegue B, and Alexander RW (1996). Angiotensin receptors and their therapeutic implications. Annu Rev Pharmacol Toxicol 36:281-306.

Hahn AW, Jonas U, Buhler FR, and Resink TJ (1994). Activation of human peripheral monocytes by angiotensin II. FEBS Lett 347:178-180.

Hall JE and Guyton AC (1990). Pathophysiology, diagnosis and management. In: Laragh $\mathrm{JH}$ and Brenner BM, editors. Hypertension. New York: Raven Press, 1105-1129.

Hisada Y, Sugaya T, Yamanouchi M, Uchida $H$, Fujimura $H$, Sakurai H, Fukamizu A, and Murakami K (1999). Angiotensin II plays a pathogenic role in immune-mediated renal injury in mice. J Clin Invest 103:627-635.

Huang XR, Holdsworth SR, and Tipping PG (1994). Evidence for delayed-type hypersensitivity mechanisms in glomerular crescent formation. Kidney Int 46:69-78.

Iwai $\mathrm{N}$ and Inagami T (1992). Identification of two subtypes in the rat type I angiotensin II receptor. FEBS Lett 298:257-260.

Kawasaki K, Yaoita E, Yamamoto T, Tamatani T, Miyasaka M, and Kihara I (1993). Antibodies against intercellular adhesion molecule-1 and lymphocyte function-associated antigen-1 prevent glomerular injury in rat experimental crescentic glomerulonephritis. J Immunol 150:1074-1083.

Klahr S and Morrissey J (1998). Angiotensin II and gene expression in the kidney. Am J Kidney Dis 31:171-176.

Lewis EJ and Couser WG (1971). The immunologic basis of human renal disease. Pediatr Clin North Am 18:467-507.

Matsusaka T, Hymes J, and Ichikawa I (1996). Angiotensin in progressive renal diseases: Theory and practice. J Am Soc Nephrol 7:2025-2043.

Mosmann TR and Coffman RL (1989). Th1 and Th2 cells: Different patterns of lymphokine secretion lead to different functional properties. Annu Rev Immunol 7:145-173.

Nataraj C, Oliverio MI, Mannon RB, Mannon PJ, Audoly LP, Amuchastegui CS, Ruiz P, Smithies O, and Coffman TM (1999). Angiotensin II regulates cellular immune responses through a calcineurin-dependent pathway. J Clin Invest 104: 1693-1701.
Owens GK (1989). Control of hypertrophic versus hyperplastic growth of vascular smooth muscle cells. Am J Physiol 257:H1755-H1765.

Sasamura H, Hein L, Krieger JE, Pratt RE, Kobilka BK, and Dzau VJ (1992). Cloning, characterization, and expression of two angiotensin receptor (AT-1) isoforms from the mouse genome. Biochem Biophys Res Commun 185:253-259.

Scheidegger KJ, Butler S, and Witztum JL (1997). Angiotensin II increases macrophage-mediated modification of low density lipoprotein via a lipoxygenase-dependent pathway. J Biol Chem 272:21609-21615.

Schreiner GF, Cotran RS, and Unanue ER (1982). Macrophages and cellular immunity in experimental glomerulonephritis. Springer Semin Immunopathol 5:251-267.

Sugaya T, Nishimatsu S, Tanimoto K, Takimoto E, Yamagishi T, Imamura K, Goto S, Imaizumi K, Hisada Y, Otsuka A, Uchida $\mathrm{H}$, Sugiura M, Fukuta K, Fukamizu A, and Murakami K (1995). Angiotensin II type 1a receptor-deficient mice with hypotension and hyperreninemia. J Biol Chem 270:1871918722.

Suzuki Y, Shirato I, Okumura K, Ravetch JV, Takai T, Tomino $Y$, and Ra C (1998). Distinct contribution of Fc receptors and angiotensin II-dependent pathways in anti-GBM glomerulonephritis. Kidney Int 54:1166-1174.

Tang WW, Qi M, and Warren JS (1996). Monocyte chemoattractant protein-1 mediates glomerular macrophage infiltration in anti-GBM Ab GN. Kidney Int 50:665-671.

Timmermans PB, Wong PC, Chiu AT, and Herblin WF (1991). Nonpeptide angiotensin II receptor antagonists. Trends Pharmacol Sci 12:55-62.

Tsutsumi K, Stromberg C, and Saavedra JM (1992). Characterization of angiotensin II receptor subtypes in the rat spleen. Peptides 13:291-296.

Unanue ER and Dixon FJ (1965). Experimental glomerulonephritis: VI. The autologous phase of nephrotoxic serum nephritis. J Exp Med 121:715-725.

Unanue ER and Dixon FJ (1967). Experimental glomerulonephritis: Immunological events and pathogenetic mechanisms. Adv Immunol 6:1-90.

Vance B and Kelly C (1994). A nephritogenic T cell clone expresses components of the renin-angiotensin system and is responsive to angiotensin II. J Am Soc Nephrol 5:772.

Yayama K, Matsui T, Takano M, Hayashi K, Nagamatsu T, Suzuki Y, and Okamoto $H$ (1995). Activation of the reninangiotensin system anti-glomerular basement membrane antibody-induced glomerulonephritis. Biol Pharm Bull 18: 411-415.

Yoshimura T, Robinson EA, Tanaka S, Appella E, and Leonard EJ (1989). Purification and amino acid analysis of two human monocyte chemoattractants produced by phytohemagglutinin-stimulated human blood mononuclear leukocytes. J Immunol 142:1956-1962. 